Marina Jovanović Milenković ${ }^{1}$, Aleksandra Vukmirović ${ }^{2}$, Dejan Milenković ${ }^{3}$

${ }^{1}$ University of Belgrade, Faculty of Organizational Sciences, Serbia

${ }^{2}$ Higher Education School for Applied Studies Belgrade Business School, Serbia

${ }^{3}$ Serbian Armed Forces General Staff, Serbia

\title{
Big data analytics in the health sector: challenges and potentials
}

DOI: 10.7595/management.fon.2019.0001

Abstract:

Research Question: The introduction of the Big Data concept in the healthcare sector points to a major challenge and potential. Motivation: Our goal is to indicate the importance of analyzing and processing large amounts of data that go beyond the typical ways of storing and processing information. The data have their own characteristics: volume, velocity and variety. There are different structures. Analysis of these data is possible with the Big Data concept. Its importance is most evident in the health sector, because the preservation of the health status of the population depends on adequate data analysis. Idea: The idea of the paper is that big health data analytics contributes to a better quality provision of health services. The process is more efficient and effective. Data: Health analytics suggests that more and more resources are being utilized globally. In order to achieve improvements, health analytics and Big data concepts play a vital role in overcoming the obstacles, working more efficiently and aiming at providing adequate medical care. Tools: The Big data concept will help identify patients with developed chronic diseases. Big data can identify outbreaks of flu or other epidemics in real time. In this way, they are managed by the healthcare system, reducing overall healthcare costs over time, and increasing revenues. Findings: A key policy challenge is to improve the outcomes of the healthcare system, data collection and analysis, security, storage and transfers. Big data are the potential to improve quality of care, improve predictions of diseases, improve the treatment methods, reduce costs. Contribution: This paper points to the challenges and potentials of Big Health Data analytics and formulates good reasons to apply the Big Data concept in healthcare.

Keywords: healthcare, health analytics, big health data analytics, challenges and potentials, quality and efficiency of care. JEL Classification: 115, M15, P47

\section{Introduction}

In modern business, organizations are increasingly introducing the Big Data concept globally. Several definitions of Big Data have been put forth to date. One of them is that Big Data involves data storage, management, analysis, and visualization of very large and complex datasets (Russom, 2011).

The term Big Data cannot be identified only with a large amount of diverse data, but rather with the techniques used in the processing of these data and ways of making important business decisions (Chen, Chiang \& Storey, 2012; Martin-Sanchez \& Verspoor, 2014). Due to these characteristics the more often used term is Big Data analytics or "analytics of large amounts of data" because its purpose is the application of advanced technology and statistical techniques for finding hidden patterns in data and generate information for making important business decisions (Mikalef, Pappas, Krogstie, \& Giannakos, 2017; Chawla \& Davis, 2013).

The Big health data analytics often has a predictive purpose: in a way, the use of relevant predictive analytical tools makes it possible to find the cure before people get affected by a specific disease (Khennou, Khamlichi, \& Chaoui, 2018). The health system involves large amounts of data - records of patients, management of data, analysis... (Choong \& Hyung, 2017). By definition, Big Data in the healthcare system relates to electronic health data, which are so large and complex that it is difficult (or impossible) to manage data on the basis of traditional software and/or hardware (Raghupathi \& Raghupathi, 2014; Groves, Kayyali, Knott \& Van Kuiken, 2013). 
Big Data in the health sector bring challenges and potentials. Many authors have written on this topic, so this paper gives an overview. The study section 2 will discuss health analytics. Then in section 3 Big Health Data analytics will be presented. After that, section 4 will present challenges and potentials for Big Data in health care. At the end of the paper, the conclusion is given along with the recommendations and suggestions.

\section{Aspects of Health Analytics}

Health analytics is a tool that is used to make decisions about health care based on health data. While such aspects of health analysts, such as the use of statistical models, data mining and support for clinical decisions, existed for decades, the availability of large amounts of data contributed to an integrated process of decision-making. Aspects of healthcare analytics are:

- Provide a combination of financial and administrative data,

- Identify areas to simplify operations and thus reduce costs,

- Research and development - monitor, evaluate and analyze new solutions,

- Clinical data provide information on the effectiveness of treatment,

- Doctor's understanding of what patients feel and how they react to treatment contributes to the expansion of services,

- Optimize efforts in managing hospital and foundation donations and grants, Allows hospitals to track physician records, patient histories, and needs to ensure the right doctor is deployed to the patients most in need,

- Provide an easier approach to track existing claims, clients, and premiums for insurance companies.

Healthcare industry worldwide has recently been faced with various challenges such as a high cost of providing health services, a high percentage of aging population, patients with chronic diseases, a significant shortage of medical experts... (Krumholz, 2014; Bates, Saria, Ohno-Machado, Shah \& Escobar, 2014).

For example, the cost of health care spending amounted to $\$ 2.6$ trillion in 2012, in the US, an estimated $17.6 \%$ of the gross domestic product (GDP), while in 2016 it amounted to about $\$ 4.1$ trillion. In the report, IMS Research shows that the costs for pharmacy drugs increased to \$ 1.2 trillion in 2016 (IMS Institute, 2012; Chen, Mao, \& Liu, 2014). Figure 1 shows a summary of the total costs by region and by year. Total operating expenses in 2006 amounted to $\$ 658$ billion, the sum in 2011 amounted to $\$ 956$ billion and in 2016 there was an increase of 1.175-1.205 billion dollars. The US has participated in costs from $41 \%$ in 2006 , followed by $34 \%$, and then $31 \%$ in 2016 . The states of the European Union participated in the costs with $19 \%$ in 2006 , followed by $17 \%$, while in 2016 they covered $13 \%$ of the total costs (IMS Institute, 2012).

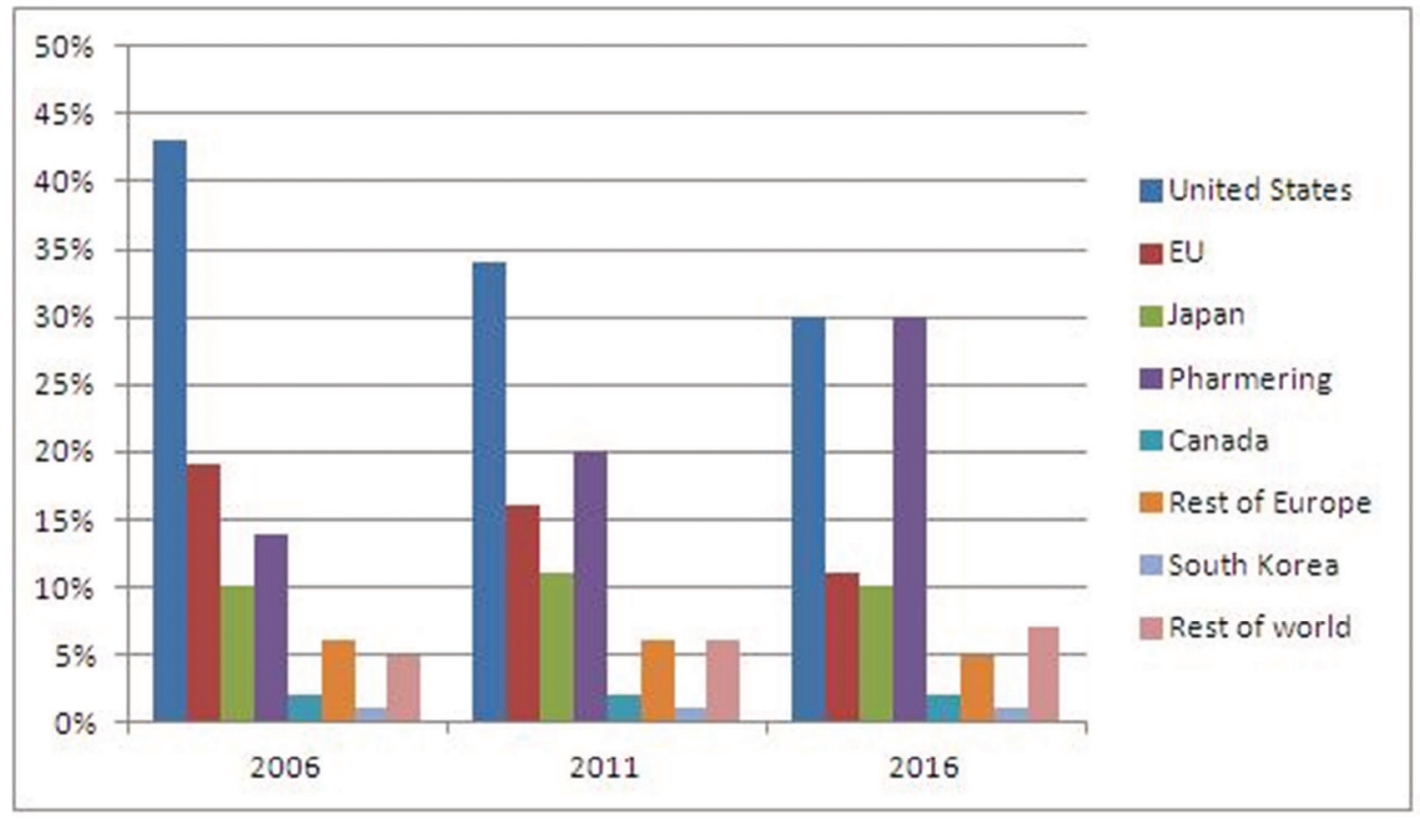

Figure 1: Cost of drugs by years and regions (adapted from IMS Institute, 2012) 
Further analysis shows that the health industry is large, but also critical. Constant investment in the health sector leads to inefficiency. According to the Institute of Medicine, one-third of health spending (about 750 billion dollars) today is lost and does not contribute to improving the health care of patients (IMS Institute, 2012; Meeker \& Hong, 2014). This refers to the various inadequate services, administrative work, unproductive work processes, inefficient service delivery, the high price of health care services, deception and missed opportunities for providing prevention (Alyass, Turcotte \& Meyre, 2015; Kim \& Groeneveld, 2017).

Costs relating to the inefficient delivery of health services are (Groves, Kayyali, Knott \& Van Kuiken, 2013) as follows:

- 130 billion dollars for an inefficient provision of health services,

- 105 billion dollars for prices that are too high,

- 190 billion dollars for excess administrative costs,

- 210 billion dollars for the unnecessary service,

- 75 billion dollars for fraud,

- 55 billion dollars for missed prevention opportunities.

The Big Data concept is as potential way to go in the quest for better efficiency of the healthcare sector (Choong \& Hyung-Jin, 2017; Sanskruti \& Atul, 2016). However, the concept also contributes to better decision-making in relation to the patient's health status, accurate diagnosis, effective treatment and better management of health data.

\section{Big Health Data Analytics}

Big data related to healthcare have rapidly expanded with the development of the Internet. Management and analysis of voluminous and varying Big data is possible using the Information-communication technology (Ryu \& Song, 2014). Such data include basic patient data, various analyses, laboratory reports, medical images, a register of doctors and nurses.

Many healthcare institutions from different countries have successfully applied solutions of Big Data in traditional healthcare. The processes that occur are improving the quality of care, increasing the effectiveness and efficiency of healthcare (Ryu \& Song, 2014; Moon-Koo \& Jong-Hyun, 2016; Witjas-Paalberends, Laarhoven, Burgwal, Feilzer, Swart, Claassen \& Jansen 2017). The effectiveness and efficiency of healthcare is the application of big data analytics to improve healthcare: 1) predictive modelling for risk and resource use; 2) population management; 3) drug and medical device safety surveillance; 4) disease and treatment heterogeneity; 5) precision medicine and clinical decision support; 6) quality of care and performance measurement; 7) public health; and 8) research applications (Rumsfeld, Joynt \& Maddox, 2016).

The concept of Big data in the health care system is characterized by several features: the volume, the variety and the velocity (Ganjir, Sarkar \& Kumar, 2016; \&, 2013). According to data from McKinsey Global Institute, the amount of data generated globally is expected to grow at an average annual rate of $41 \%$. In the period from 2008 to 2020, this amount will increase by 44 times, from 0.8 zettabytes in 2008 to 35 zettabytes in 2020 (Nasscom and Crisil Global Research \& Analytics, 2016). This is supported by the fact that every day on Facebook 10 terabytes of data and on Twitter 7 terabytes of data are generated (Groves, Kayyali, Knott \& Van Kuiken, 2013). The highest volume of health data is collected in North America (Nasscom and Crisil Global Research \& Analytics, 2016).

New data are generated at high speed, which is far greater than the speed of data processing. Health data by various sources can be collected by monitoring the health status of individuals or of the entire population (Kyoungyoung \& Gang, 2013). However, different stakeholders have different goals and hopes for Big Data analytics (Jovanovic Milenkovic, Milenkovic, Vukmirovic \& Radojicic, 2016):

- Physicians - to improve better medical care;

- Patients - want daily use of new technologies in order to get better care with the proper diagnosis;

- Providers - want access to data of the clinic, the patients, in order to improve decision making, achieving efficiency in the work without error;

- Researchers - want a new tool to improve the quality and quantity of the workflow. These include the various statistical tools and algorithms;

- Pharmaceutical companies - they want to better understand the causes of disease and thus get a safer drug market; 
- Mobile devices producers - data provided by the various mobile health applications integrated into the mobile devices (heart beep, physical activity, sports and recreation, sleeping habits etc.)

- Government - trying to reduce costs, enforce regulations;

- Company's software development - see the opportunities to serve the wholesale market, to develop software that will find application in the health system.

The US health care system faces the problems of the health insurance. Resolving these problems has been described by the former US President Barack Obama, who states that The Affordable Care Act has made a significant progress towards solving long-standing challenges related to access, affordability and quality of care (Barack, 2016). In March 2012, the former US President Barack Obama and his administration launched an initiative to approve \$200 million for the project "Big Data Research and Development Initiative" whose main objective is to transform the use of Big Data for scientific discovery and biomedical research, with the participation of several federal departments (Kyoungyoung \& Kim, 2013; Weiss \& Zgorski, 2012; Chen, Mao \& Liu, 2014). The Obama administration proposed a program "Health 2.0" for efficient data management: patients, medical institutions, health insurance. One of the proposed models in the "Health 2.0" is a Pillbox. Pillbox involves providing accurate information about specific drugs that the patient is interested in. The aim of Pillbox is to reduce costs in the sale of drugs to keep medical records in order to avoid inadequate selling of drugs. It is believed that the service is necessary for the elderly (Sagiroglu \& Sinanc 2013; Kyoungyoung \& Kim, 2013). A report by McKinsey Global Institute suggests that if the US healthcare were to use Big Data creatively and effectively, the sector could create more than $\$ 300$ billion in value every year. Two-thirds of the value would be in the form of reducing the US healthcare expenditure (Manyika Chui, Brown et al., 2011; Belle, Thiagarajan, Soroushmehr, Navidi, Beard \& Najarian, 2015)

By applying the Big Data analytics, physicians can make timely decisions. The Big Data concept will help identify patients with developed chronic diseases, such as diabetes, heart failure or chronic obstructive pulmonary disease (Fong, $\mathrm{Ng} \&$ Yuen, 2017). In this way, the data are connected, identifying patients who need additional care (Nasser \& Tariq, 2015). An early prevention of diseases start with a change of the lifestyle. Management of these diseases is significant because they are the most costly to treat. Big data can be tracked by software and thus identify outbreaks of flu or other epidemics in real time. In this way, they are managed by the health system, reducing overall healthcare costs over time, and increasing revenues (Murdoch \& Detsky, 2013).

\section{Challenges and Potentials}

A key policy challenge in both developing and developed countries is to improve outcomes of the healthcare system while containing cost pressures. Furthermore, health care costs are rising rapidly, driven by population ageing and rising relative prices. To improve public healthcare spending projections and meet a rapidly growing health care demand, efficiency gains in health care will be crucial (Mitrovic, Vujosevic \& Savic, 2016).

The potential of the Big Data concept can help healthcare organizations improve quality and efficiency in the following (Luna, Mayan, García, Almerares \& Househ, 2014):

- It leads to new knowledge, based on the analysis of data, that can provide solutions to some of the problems that cannot otherwise be detected in clinical conditions;

- disseminating knowledge, helping physicians through clinical decision support systems, which can provide suggestions and predictions in real time based on the personal data of patients;

- translating personalized medicine initiatives into clinical practice by providing the opportunity to use analytical capabilities;

- Empowering patients - patients can be informed of their health and healthcare;

- Improving epidemiological surveillance: some tools are developed and keep track of the highly prevalent or deadly diseases in the population.

Big data have the potential to improve patient care, save lives and reduce healthcare costs (Srinivasan \& 2013; Koumpourosm, 2014). The potential health lies in combining traditional details with new forms of data at the individual level and at the population level. In Table 1, the differences between traditional analytics and Big Data analytics are shown in relation to the data sources, processing techniques, intensity, time and purpose of data processing. 
Table 1: Traditional vs. Big Data analytics (Lazarevic, 2015)

\begin{tabular}{|l|l|l|}
\hline Parameter & Traditional analytics & Big Data analytics \\
\hline Data capture & Analysis of the data part (Partial Data) & Analysis of all the data (All Data) \\
\hline Sources & $\begin{array}{l}\text { A small number of homogeneous data } \\
\text { sources }\end{array}$ & $\begin{array}{l}\text { A large number of heterogeneous } \\
\text { data sources }\end{array}$ \\
\hline Data processing techniques & $\begin{array}{l}\text { Standard tools and techniques } \\
\text { (classic software, classical } \\
\text { statistical techniques) }\end{array}$ & $\begin{array}{l}\text { Advanced tools and techniques } \\
\text { (advanced software, advanced } \\
\text { statistical techniques) }\end{array}$ \\
\hline Time data processing & After generating the data (Ex-Post) & $\begin{array}{l}\text { During the generating of the data } \\
\text { (Real-Time) }\end{array}$ \\
\hline The intensity of data processing & Occasional data processing (Ad-Hoc) & Continuous data processing \\
\hline The goals of data processing & Diagnosis and description of the event & $\begin{array}{l}\text { Behavioural analysis and } \\
\text { forecasting of events }\end{array}$ \\
\hline Types of reports & Standard uniform reports & Complex reports \\
\hline
\end{tabular}

Table 1 shows that Big Data analytics reveals many advantages. Big data in the health sector mainly consist of huge amounts of digital health data such as electronic health records (EHR), computerized physician order entry (CPOE), picture archiving communications system (PACS), clinical decision support systems (CDSS), and laboratory information systems.

The following factors lead to the improvement of quality of healthcare (Archenaa \& Anita, 2015):

- Providing patient centric services:

This involves detecting diseases at the earlier stages based on the clinical data available, minimizing drug doses to avoid side effects, and reducing cost for the patients.

- Detecting spreading diseases earlier:

Predicting the viral diseases earlier before their spreading, based on the live analysis. Preventive measures shall be taken in a particular geo-location.

- Monitoring the hospital's quality:

All hospitals must apply the norms issued by the medical council. This periodical monitoring indicates necessary measures against disqualifying hospitals.

- Improving the treatment methods:

Customized patient treatment - Doctors monitor patients suffering from certain diseases. Based on the analysis of data, doctors can give the persons who may suffer from the same symptoms, the same drugs that lead to healing.

In the literature, many authors gave their views on the challenges and potentials provided by Big Data. Electronic health records are designed and implemented to move data between disparate organizations, provide a follow up of patients, and develop strategies to improve overall outcomes. Cloud storage is increasingly used, because costs drop and reliability grows. A large number of healthcare organizations use some sort of cloud-based health IT infrastructure, including storage and applications. The Security Rule includes a long list of technical safeguards for organizations storing protected health information, including transmission security, authentication protocols, and controls over access, integrity, and auditing (Alekxandru, Radu \& Bizon, 2018). Table 2 lists the main challenges and potentials for big data in health care.

Table 2: The challenges and potentials of health Big data analytics

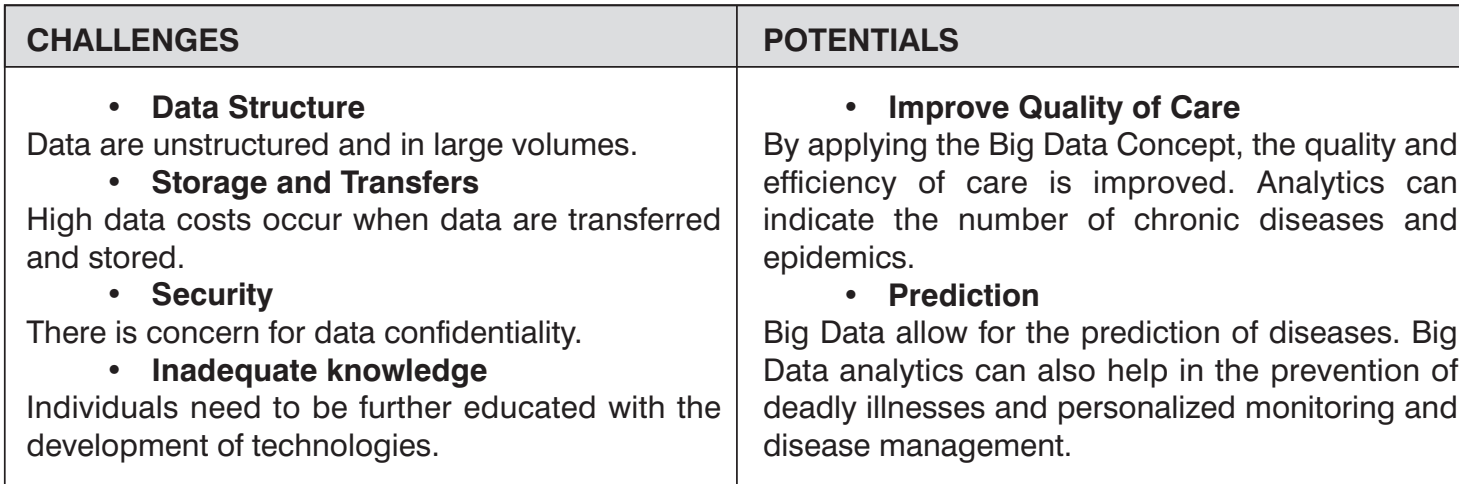




\begin{tabular}{|c|c|}
\hline CHALLENGES & POTENTIALS \\
\hline $\begin{array}{l}\text { - Data Standardization } \\
\text { Data are not standardized, which leads to data } \\
\text { transmission problems. } \\
\text { - Regulatory Compliance } \\
\text { Legal considerations should be taken when Big } \\
\text { Data are analyzed. }\end{array}$ & $\begin{array}{l}\text { - Upgrade operational proficiency } \\
\text { Early analysis is important in offering better } \\
\text { attention and care. } \\
\text { - Data Quality, Structure, } \\
\text { and Accessibility } \\
\text { Rapid capture of data and converting primary, raw } \\
\text { and unstructured data into meaningful information. } \\
\text { The data is transparent and accessible. } \\
\text { - Improve Decision Making } \\
\text { Health care providers make more informed } \\
\text { decisions. This, in turn, improves the quality of care } \\
\text { provided to the patients. } \\
\text { - Cost Reduction } \\
\text { Big data reduce costs and increases revenue. } \\
\text { - Patient-Centric Care } \\
\text { The Big Data concept introduces the patient into } \\
\text { active part in his healthcare. } \\
\text { B Globalization } \\
\text { By globalizing data, Big Data are available to all } \\
\text { regions. }\end{array}$ \\
\hline
\end{tabular}

Management challenges related to Big data are a group of challenges encountered, for example while accessing, managing and governing the data. Data warehouses store massive amounts of sensitive data such as financial transactions, medical procedures, insurance claims, diagnosis codes, personal data, etc (Sivarajah, Kamal, Irani \& Weerakkody, 2017). The health information scientists and computer scientists discussed big data in medicine. They focused on how to collect, store, integrate, and manage data. However, the future of big data in health sector is in using new analytic techniques such as machine learning to answer clinical questions, educating doctors and policy makers to understand big data, and promoting the use of tools generated by big data and big data technologies that support clinical decision making. In the future, it is important to discover the challenges and potentials that health Big Data analytics provides (Zhang, Wang, Zhan \& Zhan, 2018).

Big Data technologies have the potential to transform the way healthcare providers use sophisticated technologies to gain insight from their clinical and other data repositories and make decisions based on collected information. In the future, we will see rapid, widespread implementation and use of Big Data analytics across the healthcare organization and the healthcare industry. Big Data analytics and applications in healthcare are at a nascent stage of development, but rapid advances in platforms and tools can accelerate their maturing process (Vukmirovic, Rajnai, Radojicic, Vukmirovic \& Jovanovic Milenkovic, 2018).

\section{Conslusion}

The goal of the health system is a healthy population (Jovanovic Milenkovic, Radojicic, Milenkovic \& Vukmirovic, 2009; Jovanovic Milenkovic, Jeremic \& Martic, 2014). Due to the expansion of information and communication technologies in all spheres of life, especially in the field of health care, the importance of theories that predict and explain the factors that influence the adoption and use of information and communication technologies in health care is growing (Rodic Trmcic, Labus, Bogdanovic, Babic \& Dacic-Pilcevic, 2016).

The concept of "Big data" is not new; however, the way it is defined is constantly changing. The introduction of Big Data concepts in the health system contributes to better health care characterized by speed, accuracy and timeliness. Health Analytics and Big Data concepts play an important role in overcoming obstacles in order to a more efficient and faster medical care. The application of new technologies is essential. Medical and health technology is used by everyone: patients, physicians, health workers, end-users, engineers, clinics and hospitals.

In this paper, our systematic literature review revealed both challenges and opportunities that big data offers to the health care industry. The literature listed the challenges of data structure, storage and transfers security and standardization. The literature also listed the opportunities of increased quality, better management of population health, prediction of diseases, cost reduction and globalization. 
Despite the complexities of healthcare data, there is a potential and benefit in developing and implementing Big Data solutions within this realm. These findings point to the direction for future research. Ultimately, the key to success will be to remain focused on ultimate goal: gaining an effective insight into the best ways to treat patients in the healthcare system (Schneeweiss, 2014).

\section{REFERENCES}

[1] Alekxandru, A.G., Radu, I. M. , Bizon, M. L. (2018). Big Data in Healthcare - Opportunities and Challenges, Informatica Economică, 22(2), DOI: 10.12948/issn14531305/22.2.2018.05

[2] Alyass, A., Turcotte, M., Meyre, D. (2015). From big data analysis to personalized medicine for all: challenges and opportunities, BMC Medical Genomics, 8:33, DOI: 10.1186/s12920-015-0108-y

[3] Archenaa, J.\& Anita, E.A.M.,(2015). A Survey Of Big Data Analytics in Healthcare and Government, Procedia Computer Science 50, 408 - 413, DOI: 10.1016/j.procs.2015.04.021

[4] Barack, O. (2016). United States Health Care Reform Progress to Date and Next Steps, The Journal of the American Medical Association, 316(5), 525-532, DOI:10.1001/jama.2016.9797

[5] Bates, W. D., Saria, S. , Ohno-Machado L., Shah A. \& Escobar G., (2014). Big Data In Health Care: Using Analytics To Identify And Manage High-Risk and High-Cost Patients, Health Affairs, 33(7):1123113, DOI: $10.1377 /$ hlthaff.2014.0041

[6] Belle, A., Thiagarajan, R., Soroushmehr, S. M. R., Navidi, F, Beard, A. D.\& Najarian, K., (2015). Big Data Analytics in Healthcare, BioMed Research International, DOI: 10.1155/2015/370194

[7] Chawla, N.V.\& Davis, D. A., (2013). Bringing Big Data to Personalized Healthcare: A Patient-Centered Framework, Journal of General Internal Medicine 28(3), 660-665, DOI:10.1007/s11606-013-2455-8

[8] Chen, H., Chiang, H. L. R. \& Storey, C.V., (2012). Business intelligence and analytics: from Big data to Big impact, MIS Quarterly, 36(4),1165-1188

[9] Chen, M., Mao, S. \& Liu, Y. (2014). Big Data: A Survey, Mobile Networks and Applications, 19: 171. DOI: 10.1007/s11036-013-0489-0

[10] Choong H. L. \& Hyung-Jin Y., (2017). Medical big data: promise and challenges, Kidney Research and Clinical Practice, 36(1), 3-11. DOI: 10.23876/j.krcp.2017.36.1.3

[11] Fong, B. Ng, A., \& Yuen, P., (2017). Sustainable Health and Long-Term Care Solutions for an Aging Population, IGI Global, 2017, ISSN: 2475-6628.

[12] Ganjir, V., Sarkar, B.K. \& Kumar, R., (2016). Big data analytics for healthcare, International Journal of Research in Engineering, Technology and Science, 6, Special Issue,1-6

[13] Groves, P., Kayyali, B., Knott, D. \& Van Kuiken, S., (2013). The 'big data' revolution in healthcare, Center for US Health System Reform Business Technology Office, McKinsey \& Company

[14] IMS Institute for Healthcare Informatics (2012). The Global Use of Medicines: Outlook Through 2016

[15] Jovanovic Milenkovic M., Jeremic V.\& Martic M., (2014). Sustainable Development in the e-Health Sector of the European Union, Journal of environmental protection and ecology, 15(1), 248-256

[16] Jovanovic Milenkovic, M., Milenkovic, D., Vukmirovic, D., \& Radojicic, Z., (2016). Telemedicine, Belgrade, Faculty of Organizational Sciences, Serbia

[17] Jovanovic Milenkovic, M., Radojicic, Z., Milenkovic, D. \& Vukmirovic, D., (2009). Applying electronic documents in development of the healthcare information system in the Republic of Serbia, Computer Science and Information Systems, 6(2), 111-126

[18] Khennou, F., Khamlichi, Y.I., Chaoui, N.E.H., (2018). Improving the Use of Big Data Analytics Within Electronic Health Records: A Case Study based OpenEHR, Procedia Computer Science 127, 60-68, DOI: 10.1016/j.procs.2018.01.098

[19] Kim, J.\& Groeneveld, W.P.,(2017). Big Data, Health Informatics, and the Future of Cardiovascular Medicine, Journal of the American College of Cardiology, 69(7) DOI: 10.1016/j.jacc.2017.01.006

[20] Koumpourosm, Y. (2014). Big data in healthcare. In: Healthcare Administration: Concepts, Methodologies, Tools, and Applications, 1st edn. IGI Global ,ISBN-13: 978-1466663398

[21] Krumholz, M.H., (2014). Big Data And New Knowledge In Medicine: The Thinking, Training, And Tools Needed For A Learning Health System, Health Affairs, 33(7),1163-1170, DOI: 10.1377/hlthaff.2014.0053

[22] Kyoungyoung, J. \& Gang,H. K., (2013). Potentiality of Big Data in the Medical Sector: Focus on How to Reshape the Healthcare System, Healthcare Informatics Research. 2013 Jun;19(2):79-85, DOI:10.4258/hir.2013.19.2.79

[23] Kyoungyoung, J.\& Kim, G., (2013). Potentiality of Big Data in the Medical Sector: Focus on How to Reshape the Healthcare System, Health Informatics Research, 19(2), 79-85, DOI: 10.4258/hir.2013.19.2.79

[24] Lazarević I., (2015), Big data u farmaciji i medicini, BB Informator, 242

[25] Luna, D, Mayan, J.C, García, MJ, Almerares, AA \& Househ, M., (2014). Challenges and potential solutions for big data implementations in developing countries, Yearbook of Medical Informatics, 15(9), 36-41. DOI: 10.15265/IY-2014-0012. 
[26] Manyika, J,M. Chui, Brown, B. et al.,(2011). Big Data:The Next Frontier for Innovation, Competition, and Productivity, McKinsey Global Institute

[27] Martin-Sanchez, F. \& Verspoor, K. (2014). Big Data in Medicine is Driving Big Changes, Yearbook of Medical Informatics, 9(1), 14-20., DOI: 10.15265/IY-2014-0020

[28] Meeker, Q. W. \& Hong, Y. (2014). Reliability Meets Big Data: Opportunities and Challenges, Quality Engineering, 26(1), 102-116

[29] Mikalef, P., Pappas, I. O., Krogstie, J., \& Giannakos, M. (2017). Big data analytics capabilities: a systematic literature review and research agenda. Information Systems and e-Business Management, 7 , 1-32, DOI: 10.1007/s10257-017-0362-y.

[30] Mitrovic, Z., Vujosevic, M. \& Savic, G.,(2016). Data Envelopment Analysis for Evaluating Serbia's Health Care System, Management, 75, DOI: 10.7595/management.fon.2015.0012

[31] Moon-Koo, K. \& Jong-Hyun, P., (2016). Identifying and prioritizing critical factors for promoting the implementation and usage of big data in healthcare, Information Development, 33(3), 257-269, DOI: $10.1177 / 0266666916652671$

[32] Murdoch, T.B. \& Detsky, A.S., (2013). The Inevitable Application of Big Data to Health Care. The Journal of the American Medical Association; 309(13),1351-2, DOI: 10.1001/jama.2013.393

[33] Nambiar, R., Bhardwaj, R., Sethi, A. \& Vargheese, R., (2013). A look at challenges and opportunities of Big Data analytics in healthcare, Big Data, 2013 IEEE International Conference on, Silicon Valley, CA, USA

[34] Nasscom and Crisil Global Research \& Analytics, (2016). The Big News About Big Data, Retrieved from: http://www.nasscom.in/big-news-about-big-data?fg $=172816$

[35] Nasser, T. \& Tariq, RS (2015). Big Data Challenges, Journal of Computer Engineering \& Information Technology, 4(3), DOI: 10.4172/2324-9307.1000135

[36] Raghupathi, W. \& Raghupathi, V. (2014), Big data analytics in healthcare: promise and potential, Health Information Science and Systems, 2: 3. DOI: 10.1186/2047-2501-2-3

[37] Rodic Trmcic, B., Labus, A., Bogdanovic, Z., Babic, D. \& Dacic-Pilcevic, A. (2016). Usability of m-Health Services: A Health Professional's Perspective, Management, 80, DOI: 10. 7595/management.fon.2016.0022

[38] Rumsfeld J.S., Joynt K.E. \& Maddox TM. (2016). Big data analytics to improve cardiovascular care: promise and challenges, Nature Reviews Cardiology. 13, 350-359. DOI: 10.1038/nrcardio.2016.42.

[39] Russom, P. (2011). Big data analytics. TDWI Best Practices Report, Fourth Quarter 1-35

[40] Ryu, S. \& Song, T-M., (2014), Big Data Analysis in Healthcare, Healthcare Informatics Research, 20(4), 247-248. DOI:10.4258/hir.2014.20.4.247

[41] Sagiroglu, S. \& Sinanc, D.(2013). Big Data: A Review, Collaboration Technologies and Systems (CTS), 2013 International Conference on, IEEE, San Diego, CA, USA

[42] Sanskruti P. \& Atul P, (2016). A big data revolution in health care sector: opportunities, challenges and technological advancements, International journal of information Sciences and Techniques, 6 (1/2), 155-162, DOI: 10.5121/ijist.2016.6216 155

[43] Schneeweiss, S. (2014). Learning from Big Health Care Data, The New England Journal of Medicine,370, 2161-2163, DOI: 10.1056/NEJMp1401111

[44] Sivarajah, U., Kamal, M. M., Irani, Z., Weerakkody, V. (2017), Critical analysis of Big Data challenges and analytical methods, Journal of Business Research, 70, 263-286, DOI: 10.1016/j.jbusres.2016.08.001

[45] Srinivasan, U. \& Arunasalam, B., (2013). Leveraging Big Data Analytics to Reduce Healthcare Costs, IT Professional, 15 (6), DOI: 10.1109/MITP.2013.55

[46] Vukmirovic, A., Rajnai, Z., Radojicic, M., Vukmirovic, J., Jovanovic Milenkovic, M., (2018), Infrastructural Model for the Healthcare System based on Emerging Technologies, Acta Polytechnica Hungarica 15(2), 33-48, DOI: 10.12700/APH.15.1.2018.2.2

[47] Weiss, R. \& Zgorski, L.J, (2012). Obama Administration Unveils “Big Data" Initiative: Announces 200 Million in new R\&D Investments, Office of Science and Technology Policy Executive Office of the President

[48] Witjas-Paalberends, E. R., Laarhoven, L. P. M. van, Burgwal, L. H. M. van de, Feilzer, J., Swart J. de, Claassen, E. \& Jansen, W. T. M. (2017). Challenges and best practices for big data-driven healthcare innovations conducted by profit-non-profit partnerships - a quantitative prioritization, International Journal of Healthcare Management, 1-11, DOI: 10.1080/20479700.2017.1371367

[49] Zhang L., Wang H., Li Q. Zhao, M.H. \& Zhan, O.M., (2018). Big data and medic research in China, British Medical Journal, 360:j5910, DOI: 10.1136/bmj.j5910

Received: 2017-12-08

Revisions requested: 2018-02-10

Revised: 2018-12-28 (3 times)

Accepted: 2019-01-09 


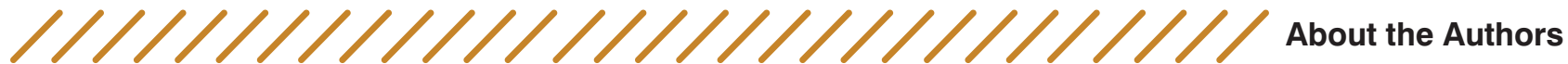

\section{Marina Jovanović Milenković \\ University of Belgrade, Faculty of Organizational Sciences, Serbia e-mail: marinaj@fon.bg.ac.rs}

Marina Jovanović Milenković is an Associate for Ph.D.studies within the Department of

Ph.D. studies at the Faculty of Organizational Sciences, University of Belgrade. She completed her PhD thesis in the field of Information and communication technology in health care management in 2011. Her major interests are e-health, ICT implementations in health systems and business decision making.

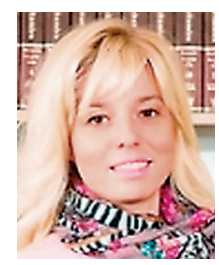

Aleksandra Vukmirović Higher Education School for Applied Studies Belgrade Business School, Serbia e-mail: aleksandra.vukmirovic@bbs.edu.rs

Aleksandra Vukmirović is a lecturer at the Belgrade Business School, Higher Education Institution for Applied Studies. She is the author of several scientific studies of national and international importance. She participated in and managed a number of projects in the fields of e-business and marketing research.

Dejan Milenković Serbian Armed Forces General Staff, Serbia e-mail: dejan.milenkovic@vs.rs

Dejan Milenković is a professional officer in the Serbian Armed Forces - General Staff. He completed his $\mathrm{PhD}$ thesis in 2013 in the fields of statistical management, electronic documents management and repositories of electronic documents. His major interests are e-business, documents management system, business process analysis and business decision making. 